\title{
THE INFLUENCE OF A DIET, HIGH IN BUTTER FAT, ON GROWTH, BLOOD FORMATION AND BLOOD DESTRUCTION
}

\author{
BY GULLI LINDH MULLER
}

(From the Thorndike Memorial Laboratory of the Boston City Hospital)

(Received for publication January 16, 1928)

The conception that a diet high in fat in some way influences blood formation and blood destruction, especially in pernicious anemia and in the anemias of infants, has been voiced repeatedly, and it has been recently re-stated by Minot and Murphy (1). The uncertainty, however, as to the effect of fat on the blood and blood-forming organs is well illustrated in the literature. Minot and Murphy (1) empirically exclude most fat from the diet of pernicious anemia patients, while Koessler and associates (2) recommend a diet for the same disease in which approximately two-thirds of the caloric intake is in form of fat, mainly derived from dairy products.

The theory that the blood forming organs are harmfully affected by excess fat and fatty.acids derived especially from milk and its products is, in a measure, supported by the prevalence of pernicious anemia in countries where the dairy industry and consequent consumption of dairy products occupy a prominent place. Moreover, pernicious anemia patients are usually well nourished in contrast to those suffering from other diseases associated with anemia, and histories of these patients show in many instances a choice of food rich in fat (1). Gibson and Howard (3) state that patients with pernicious anemia do not do well when butter is added to their diet. Hammarsten (4) points out that fat people as a rule tend to have less hemoglobin than thin people. Czerny $(5 \mathrm{a})$ claims that injurious agents present in milk produce anemia in infants. These agents are said to be fatty acids which cause an increase of blood destruction (6). As proof for this is cited the improvement which takes place as soon as milk is limited and other food products substituted. Stoeltzner (7) pointed out that a severe hemolytic anemia could be produced in children by goat's 
milk. This anemia disappeared as soon as the milk was eliminated. Whether, however, all these anemias of infants are due to excess fat may be questioned. Milk is very low in iron (8) and experimental anemias may be produced by milk diet and cured by the addition of iron (9) (10). It is also claimed that a vitamin deficiency may account for the anemia of infants fed exclusively on milk (11).

This paper deals with the effect of a high fat diet on the blood and blood-forming organs of the rat, and the evidence tends to show that if all the other necessary constituents of the diet are present, an excess of fat derived from milk exclusively does not of itself impede either growth or blood formation.

\section{EXPERIMENTAL}

Sixteen healthy rats were used. Of these eight were put on the stock diet of the laboratory to which was added milk, butter, bread, meat, celery and carrots, thus insuring a thoroughly mixed diet. The remaining eight were fed a high fat diet in which 86.5 per cent of the caloric intake was derived from butter fat. (See table 1.) The protein was supplied by pure casein, and the salt mixture was the one recommended by Osborne and Mendel (12a). The creamery butter was washed repeatedly to free it from any salts, then cooled to low temperature and the water removed carefully. The dry ingredients of the diet were thoroughly mixed after weighing, and then gradually worked into the butter to insure a complete mixture. Two kilograms of the mixture were made at a time and the food was kept in the ice box between feedings. The consistency of the mixture was such that no scattering of the food was possible, thus insuring fairly accurate measure of the quantities consumed. To this diet was added a small piece of carrot or celery twice a week to provide some bulk and any possible constituent necessary for maintenance and growth as it was desirable to exclude as far as possible all factors influencing growth unfavorably except, potentially, the fat. This very small amount of vegetables has been disregarded in calculations of the diets. The food of the group on the high fat diet was carefully weighed during the whole of eight months and at no time were the dishes allowed to be empty. All the rats were kept in individual wire cages with raised bottoms, and fresh water was supplied freely. Examinations of 
freely flowing blood from the tip of the tail were done twice a month. At the end of the experiment Zenker fixed tissues, stained with eosin and methylene blue, and for iron with the potassium ferri-cyanide method, were studied.

Each group of animals included $(a)$ young rats, born in the laboratory and put on the diet at the age of 6 to 7 weeks; (b) mature animals about 24 months old.

The growth of the young animals proceeded at a rapid rate. The initial weight (see table 2) of four of them on high fat diet was doubled respectively in 86 (no. 39), 69 (no. 62), 47 (no. 61), and 44 (no. 37) days. The controls doubled their weight in 63, 56, 42 and 41 days. Most of the animals weighed over 100 grams before they were put on the

TABLE 1

Composition of high fat diet

\begin{tabular}{|c|c|c|c|}
\hline & $\begin{array}{c}\text { Weight, per } \\
\text { cent }\end{array}$ & $\begin{array}{l}\text { Calories } \\
\text { in } 1000 \text { grams }\end{array}$ & $\begin{array}{l}\text { Per cent of } \\
\text { calories }\end{array}$ \\
\hline 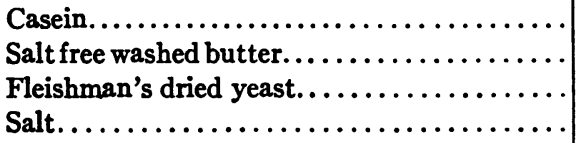 & $\begin{array}{r}20 \\
71 \\
5 \\
4\end{array}$ & $\begin{array}{r}820 \\
6,603 \\
205^{*}\end{array}$ & $\begin{array}{r}10.7 \\
86.5 \\
2.6\end{array}$ \\
\hline
\end{tabular}

* The caloric value of Fleishman's yeast has been arbitrarily chosen as 4.1 calories per gram.

diet. The periods for doubling the weight are therefore longer than those reported by other observers as, for example, Hopkins (13) who found that starting with an initial weight of about 50 grams, the males ( 76 per cent) doubled their weight in 2 weeks, while females as a rule gained more slowly and irregularly.

All the animals of adult size on the high fat diet maintained and added to their weight (table 2). Toward the end of the experiment, however, they had dry, thin fur, and one of them a scab-like eruption on the neck. As slight dryness of the hair was also observed in one of the young animals on the high fat diet and in none of the controls, it may have some significance, in relation to the diet, worthy of investigation. The same phenomenon was observed by Frank (14) in his series of rats fed on high fat diet and he suggests that it may be due to the excess or disproportion of vitamin A in comparison with the 
other vitamins. He found that feeding carrots from the beginning prevented the skin affection, and adding carrots to the diet after the eruption had appeared caused improvement. He also quotes Czerny (5b), who observed that tuberculous children fed 80 grams of cod

TABLE 2

\begin{tabular}{|c|c|c|c|c|c|c|c|c|}
\hline \multirow{2}{*}{ Number } & \multicolumn{2}{|c|}{ Red blood cells } & \multicolumn{2}{|c|}{ Hemoglobin } & \multirow{2}{*}{$\begin{array}{l}\text { White } \\
\text { blood } \\
\text { cells- } \\
\text { average } \\
\text { during } \\
\text { period }\end{array}$} & \multirow{2}{*}{$\begin{array}{l}\text { Initial } \\
\text { weight }\end{array}$} & \multirow{2}{*}{$\underset{\text { weight }}{\text { Final }}$} & \multirow{2}{*}{$\begin{array}{l}\text { Gain of } \\
\text { weight }\end{array}$} \\
\hline & $\begin{array}{c}\text { Average } \\
\text { during } \\
\text { period }\end{array}$ & Final & $\begin{array}{l}\text { Average } \\
\text { during } \\
\text { period }\end{array}$ & Final & & & & \\
\hline
\end{tabular}

High fat. Growing rats

\begin{tabular}{c|c|c|c|c|c|c|c|c}
\hline & millions & millions & per cent & per cent & thousands & grams & grams & grams \\
$39 \%$ & 8.6 & 8.3 & 76 & 88 & 12.3 & 102 & 262 & 160 \\
$37 \sigma^{7}$ & 9.8 & 10.3 & 80 & 83 & 11.1 & 84 & 368 & 284 \\
$61 \sigma^{7}$ & 9.8 & 9.9 & 87 & 99 & 9.3 & 136 & 443 & 307 \\
$-62 \sigma^{7}$ & 9.7 & 10.0 & 81 & 83 & 7.0 & 139 & 424 & 285 \\
\hline
\end{tabular}

Controls

\begin{tabular}{r|r|r|r|r|r|r|r|r}
\hline $65 \%$ & 9.0 & 9.9 & 82 & 104 & 16.7 & 120 & 279 & 159 \\
$63 \sigma^{7}$ & 10.0 & 11.1 & 87 & 111 & 10.4 & 134 & 477 & 343 \\
$64 \sigma^{7}$ & 9.9 & 11.4 & 87 & 104 & 10.2 & 136 & 480 & 344 \\
$66 \sigma^{7}$ & 10.3 & 10.6 & 85 & 111 & 10.6 & 135 & 450 & 315 \\
\hline
\end{tabular}

High fat. Adult rats

\begin{tabular}{l|l|l|l|l|l|l|l|l}
\hline $18 \%$ & 8.4 & 9.5 & 80 & 76 & 10.7 & 244 & 277 & 33 \\
$19 \%$ & 8.5 & 9.1 & 83 & 77 & 19.2 & 284 & 315 & 31 \\
$20 \%$ & 8.9 & 8.5 & 77 & 70 & 15.3 & 262 & 286 & 24 \\
$21 \%$ & 9.1 & 9.3 & 88 & 80 & 16.3 & 261 & 317 & 56 \\
\hline \multicolumn{1}{c}{ Controls } \\
\hline $34 \%$ & 9.0 & 9.2 & 79 & 73 & 13.9 & 234 & 284 & 50 \\
$35 \%$ & 9.3 & 9.7 & 89 & 88 & 11.4 & 257 & 315 & 58 \\
\hline
\end{tabular}

liver oil daily developed eczema which disappeared as soon as the cod liver oil was withdrawn.

The daily food consumption per 100 grams of live weight, calculated for the entire eight month period, varied from 3.26 to 3.55 grams for the adult group, and from 3.35 to 4.57 grams for the young rats. This, 
expressed in calories, is from 24.9 to 27 calories for the adult group and from 25.6 to 34.7 for the young rats. The distribution of the caloric intake is illustrated in table 3 . From the examination of this table it will be seen that for the two young rats put on the diet in April, the caloric intake per 100 grams live weight remained high for the first three months and then suddenly dropped in July. Num. bers 61 and 62, put on the diet in the beginning of June, showed a high caloric intake and a gain of 108 and 88 grams respectively for the first month. There was a sudden drop in the caloric intake in July;

TABLE 3

Average caloric intake per day for 100 grams of live weight

\begin{tabular}{|c|c|c|c|c|c|c|c|c|c|c|c|}
\hline Number & March & April & May & June & July & August & Septem- & $\begin{array}{c}\text { Octo- } \\
\text { ber }\end{array}$ & $\begin{array}{c}\text { Novem- } \\
\text { ber }\end{array}$ & $\begin{array}{c}\text { Decem- } \\
\text { ber }\end{array}$ & $\underset{\text { ary }}{\text { Janu- }}$ \\
\hline
\end{tabular}

High fat diet. Growing rats

\begin{tabular}{l|l|l|l|l|l|l|l|l|l|l|l}
\hline $37 \sigma^{7}$ & & 59.2 & 42.8 & 40.9 & 24.2 & 25.2 & 27.9 & 24.0 & 21.5 & & \\
39 \% & & 39.0 & 39.7 & 40.6 & 29.9 & 31.1 & 32.7 & 23.7 & 19.8 & & \\
$61 \sigma^{7}$ & & & & 51.9 & 28.2 & 28.4 & 22.9 & 25.2 & 16.2 & 19.6 & 18.6 \\
$62 \sigma^{7}$ & & & & 53.0 & 29.1 & 31.4 & 29.1 & 28.3 & 18.0 & 22.1 & 20.3 \\
\hline
\end{tabular}

High fat diet. Adult rats

\begin{tabular}{c|c|c|c|c|c|c|c|c|c|c|c}
\hline $18 \%$ & 34.0 & 27.9 & 25.8 & 27.9 & 23.7 & 23.6 & 24.8 & 22.1 & & & \\
$19 \%$ & 30.7 & 25.5 & 20.4 & 28.2 & 23.1 & 22.2 & 26.6 & 23.4 & & & \\
$20 \%$ & 36.4 & 27.9 & 23.7 & 31.6 & 26.1 & 23.1 & 24.1 & 26.9 & & & \\
$21 \%$ & 35.5 & 25.2 & 28.5 & 27.9 & 22.1 & 14.1 & 26.1 & 19.9 & & \\
\hline $\begin{array}{c}\text { Av- } \\
\text { erage }\end{array}$ & 34.1 & 26.6 & 24.6 & 28.9 & 23.7 & 20.7 & 25.4 & 23.1 & & & \\
\hline
\end{tabular}

then a gradual decline. In the adult rats, with very slight gain of weight, the caloric intake during the first month exceeded that in any of the others, and in July and especially August the consumption was low.

That the caloric requirements of the rat display a tendency to diminish with the increasing duration of the experiment has been shown by Macallum (15). One may add that the season also influences the consumption of food, the hot summer months showing a definite drop in the caloric intake, without, in these experiments, any tendency to loss of weight. 
In table 2 the average red blood cell count during the entire period is recorded with the final count. In the young rats the final count as a rule is somewhat higher than the average, on account of the lower counts obtained during the period of growth. The same holds true of the hemoglobin. Although both the red blood cells and the hemoglobin are slightly lower in the animals fed on a high fat diet, they are well within normal limits as found in this laboratory in a series of $\mathbf{1 5 0}$ apparently healthy rats. The slightly lower hemoglobin may perhaps be due to a deficient intake of inorganic salts because of the high caloric diet. From the evidences at hand, however, there is no injurious effect on the blood-forming organs of the rat from an extremely high diet of milk fat.

In the adult rats the red blood cells stayed at approximately the same level throughout the experiment. The final hemoglobin tended to be lower in all the animals both in the high fat group and the controls. Possibly an age factor plays some rôle.

At necropsy nothing abnormal was noted in the animals on a high fat diet except excessive increase of abdominal fat. Microscopic examination of the bone marrow showed slight increase in fat cells but the blood forming constituents were entirely normal. The liver showed fatty infiltration in 6 out of 7 animals studied. This was marked in one case, moderate in two, and slight in three. In the eight controls two showed slight fatty infiltration of the liver.

Levine and Smith (16) in their experiments with high fat diet of shorter duration than the above found sections of the liver normal in structure and devoid of fat droplets.

\section{DISCUSSION}

That rats can grow on a diet in which the caloric intake of fat represents from 80 to 90 per cent of the total food has been shown by Osborne and Mendel (12b). They were able to secure growth in some of their rats and the failures were explained by the deficient intake of protein and salts due to the high caloric diet. Smith and Carey (17) were unable to secure growth in their rats at a normal rate after 50 days on a ration containing 86 per cent fat calories, derived from lard and cod liver oil, while Levine and Smith (16) feeding the same percentage of fat from the same sources secured normal, or slightly below 
normal, growth from 30 to 180 grams in body weight. They concluded that rats grew as efficiently on a high fat diet as on a mixed diet and that the fat was utilized almost completely. Frank (14) feeding a ration of milk fat as high as 91 per cent of the caloric intake to rats found that the animals on the fat ration grew more rapidly than groups fed on a high carbohydrate diet or a normal diet.

The results of the experiments reported in this paper confirm those of the above authors, showing definitely that rats can grow to adult size and that adult rats can maintain and add to their weight over a period of eight months on a diet in which 86.5 per cent of the caloric intake is in the form of butter fat.

The relation of a high fat diet to blood formation and blood destruction has been deduced mainly from clinical observations. That a lack of fat in the diet and primarily perhaps a lack of the fat soluble vitamins will cause a rapid general decline accompanied by anemia has been demonstrated by Koessler and associates (2). In experiments on rats subject to diets in which the vitamins were insufficient or lacking, Weitbrecht (18) found that fat in the form of olive oil caused a more rapid fall of blood cells and hemoglobin and a shorter course before death supervened, than the standard vitamin free diet alone. Anemia was not found in all the animals fed on a fat and vitamin free diet. The author therefore concluded that for the production of anemia constitutional factors are necessary. The anemia which occurred in the animals fed with fat as well as in the older adipose animals fed on a vitamin free diet ran a more severe course and went into an aplastic form. As an explanation for this Weitbrecht considered either an injurious effect of the fat in itself, or a similar effect from the fat in a vitamin free milieu. McCarrison (19) also found that a degree of avitaminosis producing a certain train of symptoms including anemia in pigeons and monkeys in the presence of excess starch, will do so twice as rapidly if there is also an excess of fat, i.e., an excessive intake of energy bearing constituents will produce symptoms with an incomplete avitaminosis as rapidly as a complete avitaminosis with energy bearing constituents not so excessive. He concludes that the greater the intake of fat and starches the greater must be the intake of vitamin B.

From the experiments by Weitbrecht and McCarrison with vitamin 
deficiency the conclusion may perhaps be drawn that fat as such is injurious because it is an energy bearing substance in a vitamin deficient milieu, and that growth, maintenance and consequently the activity of the blood forming organs is impaired through the lack of the essential vitamins. That butter fat as such, all the other constituents of the diet being satisfactory, does not injure or inactivate blood formation or increase blood destruction in rats, the experimental animal of preference in nutritional studies, has been definitely shown in this study.

To summarize, therefore, young rats will grow to adult size, adult rats will maintain and add to their weight on a diet containing 86.5 per cent of the total calories as butter fat, fed over a period of eight months, without the development of an anemia and without any apparent injury to the blood-forming organs.

\section{CONCLUSIONS}

The effect of a diet with 86.5 per cent of the caloric intake in the form of butter fat was studied on growing and adult rats, with reference to growth, maintenance, blood formation and blood destruction, over a period of eight months.

1. Young rats grew to adult size and adult rats maintained and added to their weight.

2. There was no evidence of injury to the blood-forming organs in either group. Slightly lower, but well within normal, hemoglobin values in the growing rats may, perhaps, be explained as the result of somewhat deficient intake of salts due to the high caloric diet.

3. Dry, thin fur was observed in the adult group and in one of the growing rats. A scab-like eruption was present in one of the adult rats.

4. The caloric intake per 100 grams of live weight decreased with the duration of the experiment in both groups.

5. The necropsy findings were normal except for increase of the abdominal fat and fatty infiltration of the liver in 6 out of 7 cases studied.

6 . The bone marrow showed slight increase in fat cells with normal blood-forming constituents.

I am indebted to the late Dr. Francis W. Peabody, who suggested the experiment and it gives me great pleasure to acknowledge his valuable advice. 


\section{BIBLIOGRAPHY}

1. Minot, G. R., and Murphy, W. P., J. Am. Med. Assoc., 1926, lxxxvii, 470. Treatment of Pernicious Anemia by a Special Diet.

2. Koessler, K. K., Maurer, S., and Loughlin, R., J. Am. Med. Assoc., 1926, lxxxvii, 476. The Relation of Anemia, Primary and Secondary, to Vita$\min$ A Deficiency.

3. Gibson, R. B., and Howard, C. P., Arch. Int. Med., 1923, xxxii, 1. Metabolic Studies in Pernicious Anemia.

4. Hammarsten, O., A Textbook of Physiological Chemistry, Translated by Mandel, J. A., 5th Ed., Wiley \& Sons, New York, 1909.

5. Czerny, A., (a) Ann. de med. et chir. inf., Paris, 1912, xvi, $609 . \quad$ L'anémie d'origine alimentaire. (b) Therap. d. gegenw., Berlin, 1912, N. F. xiv, 49. Beitrag zur Lebertrantherapie.

6. Kleinschmidt, H., Jahrb. f. Kinderheilk, 1916, Ixxxiii, 97. U'ber alimentäre Anämie und ihre Stellung unter den Anämien des Kindesalters.

7. Stoeltzner, W., Munch. Med. Wchnschr., 1922, lxix, 4. Ueber Ziegenmilchanämie.

8. Bunge, G., Z. Biol., 1904, xlv, 532. Der Kalk- und Eisengehalt unserer Nahrung.

9. Hart, E. B., Steenbock, H., Elvehjem, C. A., and Waddell, J., J. Biol. Chem., 1925, lxv, 67. Iron in Nutrition. I. Nutritional Anemia on Whole Milk Diets and the Utilization of Inorganic Iron in Hemoglobin Building.

10. Mitchell, H. S., and Schmidt, L., J. Biol. Chem., 1926, lxx, 471. The Relation of Iron from Various Sources to Nutritional Anemia.

11. Finkelstein, H., Lehrbuch der Säuglingskrankheiten, 1921, Julius Springer, Berlin.

12. Osborne, T. B., and Mendel, L. B., (a) J. Biol. Chem., 1919, xxxvii, 572. The Nutritive Value of the Wheat Kernel and its Milling Products. (b) J. Biol. Chem., 1924, lix, 13. Nutrition and Growth on Diets Highly Deficient or Entirely Lacking in Preformed Carbohydrates.

13. Hopkins, F. G., J. Physiol., 1912, xliv, 425. Feeding Experiments Illustrating the Importance of Accessory Factors in Normal Dietaries.

14. Frank, A., Monatschr. Kinderheilk., 1922, xxiv, 487. Tierexperimentelle Untersuchungen über Fetternährung.

15. Macallum, A. B., 1919, Tran. Roy. Canada Inst., Toronto.

16. Levine, H., and Smith, A. H., J. Biol. Chem., 1927, lxxii, 223. Growth Experiments on Diets Rich in Fat.

17. Smith, A. H., and Carey, E., J. Biol. Chem., 1923, Iviii, 425. Growth on Diets High in Carbohydate and High in Fat.

18. Weitbrecht, E., Arch. f. Kinderheilk, 1922, lxxi, 192. Experimentelle Untersuchungen über den Einfluss vitaminfreier Kost auf das Blut wachsender Ratten.

19. McCarrison, R., Studies in Deficiency Disease, Oxford Medical Publication, 1921, Henry Frowde and Hodder \& Stoughton, London. 